\title{
FORMULATING ALCOHOL-INFLUENCED DRIVER'S INJURY SEVERITIES IN INTERSECTION-RELATED CRASHES
}

\author{
Qiong Wu, Guohui Zhang \\ Dept of Civil Engineering, University of New Mexico, United States
}

Submitted 8 September 2014; resubmitted 2 December 2014; accepted 30 March 2015
published online 29 February 2016

\begin{abstract}
Approximately one third of all traffic fatal crashes are alcohol-related in the US according to the National Highway Traffic Safety Administration (NHTSA), alcohol-related crashes cost more than $\$ 37$ billion annually. Considerable research efforts are needed to understand better significant causal factors for alcohol-related crash risks and driver's injury severities in order to develop effective countermeasures and proper policies for system-wide traffic safety performance improvements. Furthermore, since two thirds of urban Vehicle Miles Traveled (VMT) is on signalcontrolled roadways, it is of practical importance to investigate injury severities of all drivers who are involved in intersection-related crashes and their corresponding significant causal factors due to control and geometric impacts on flow progression interruptions. This study aims to identify and quantify the impacts of alcohol/non-alcohol-influenced driver's behavior and demographic features as well as geometric and environmental characteristics on driver's injury severities around intersections in New Mexico. The econometric models, multinomial Logit models, were developed to analyze injury severities for regular sober drivers and alcohol-influenced drivers, respectively, using the crash data collected in New Mexico from 2010 to 2011. Elasticity analyzes were conducted in order to understand better the quantitative impacts of these contributing factors on driver's injury outcomes. The research findings provide a better understanding of contributing factors and their impacts on driver injury severities in crashes around intersections. For example, the probability of having severe injuries is higher for non-alcohol-influenced drivers when the drivers are 65 years old or older. Drivers' left-turning action will increase non-alcohol-influenced driver injury severities in crash occurring around intersections. However, different characteristics are captured for alcohol-influenced drivers involved in intersection-related crashes. For example, more severe injuries of alcohol-influenced drivers can be observed around intersections with three or more lanes on each approach. The model specifications and estimation results are also helpful for transportation agencies and decision makers to develop cost-effective solutions to reduce alcohol-involved crash severities and improve traffic system safety performance.
\end{abstract}

Keywords: injury severity; alcohol-influenced drivers; discrete choice model; intersection-related crashes; traffic safety.

\section{Introduction}

Statistical data indicate that traffic crashes are the leading cause of death for the age group of 4-34 years in the US (Williams et al. 2012). Alcohol-influenced driving considerably increases crash risks and severities. Nearly one third of all vehicle crash fatalities are related to alcohol-influenced drivers and 10839 people were killed in alcohol related crashes in the US in 2009 according to the National Highway Traffic Safety Administration (NHTSA 2009). Correspondingly, alcohol-related vehicle crashes cost more than $\$ 37$ billion annually (NHTSA 2009). Due to the continuous, substantial efforts undertaken by transportation agencies, the number of traffic fatalities and serious injuries has declined during the past decade. For example, in the State of New Mexico, the overall fatality rate reduced from 2.18 to 1.37 per 100 million Vehicle Miles Traveled (VMT) during the time period from 2004 to 2009 , although its crash death rate (defined as the total number of crash deaths per 100,000 population) was still $63 \%$ higher than the national average rate and ranked 12th worst among the 50 states in the US in 2009 (NMDOT 2010). Among these total fatalities, about $41 \%$ are related to alcoholinfluenced drivers (NMDOT 2010). The New Mexico 2009 rate of alcohol-involved crash deaths per 100000 population was 5.67 , which is $61 \%$ higher than the national rate, 3.53, $71 \%$ higher than the Arizona rate, 3.32, $80 \%$ higher than the Colorado rate, 3.14 , and $294 \%$

Corresponding author: Guohui Zhang

E-mail: guohui@unm.edu 
higher than the Utah rate, 1.44 , in the peer regions of southwest in the US (NMDOT 2010). In 2009, a total of 361 people were killed in traffic crashes and 114 fatalities associated at least one driver had a Blood Alcohol Concentration (BAC) of $0.08 \%$ or above in New Mexico (NHTSA 2009). These data suggest that considerable research efforts are needed to understand better significant causal factors for alcohol-involved traffic crash risks and severities in order to develop effective countermeasures and proper policies for system-wide traffic safety performance improvements.

Furthermore, two-thirds of urban VMTs are on signal-controlled roadways (FHA 2011, 2012), and in urban areas, motorists are more likely to be involved and injured in head-on collisions and red light running crashes (FHA 2009). Based on the Fatality Analysis Reporting System (FARS) and National Automotive Sampling System General Estimates System (NASS-GES) data, about $40 \%$ of the estimated 5505000 crashes that occurred in the US in 2009 were intersection-related crashes (NHTSA 2009). Therefore, intersections are particularly crash-prone areas, and it is of practical importance to investigate the significant causal factors for intersection-related crashes and study their impact on driver injury severities. Although previous studies have investigated contributing factors for alcohol-involved crashes (Maistros et al. 2014; Traynor 2005), few of them emphasized on alcohol-involved crashes occurring around intersection. In order to address this gap, the present study aims to identify and quantify the impacts of alcohol/non-alcohol-influenced driver's behavior and demographic features as well as geometric and environmental characteristics on driver injury severities around intersections in the State of New Mexico. The transportation econometric models, multinomial Logit regression models(which are mostly used discrete choice models that are able to identify contributing factors affecting driver injuries), were developed to analyze injury severities for regular sober drivers and alcohol-influenced drivers, respectively, using the crash data collected in the State of New Mexico from 2010 to 2011. Elasticity analyzes, which illustrate the magnitude of factors impacts on severity outcomes if the values of factors are changed by one unit, were conducted in order to understand better the quantitative impacts of these contributing factors on driver injury outcomes. The research findings provide a better understanding of contributing factors and their significant impacts on driver injury severities in crashes around intersections. The model specifications and estimation results are also helpful for transportation agencies and decision makers to develop cost-effective solutions to reduce alcohol-involved crash severities and improve traffic system safety performance.

\section{Literature Review}

Numerous studies have been conducted to investigate alcohol-influenced driver's behavior and characteristics as well as their impacts on crash severities. Traynor's
(2005) analyzed the impact of alcohol on average crash severities and concluded that crashes in which alcoholinfluenced drivers are more likely to get involved in a severe injury or fatality than sober drivers. Demetriades et al. (2004) analyzed alcohol and illicit drug intoxication in trauma fatalities and their association with the nature and severity of injuries, and found that 256 out of 600 victims (e.g. about $42.7 \%$ ) tested positive for alcohol and illicit drug usages. On the other hand, Smink et al. (2005) investigated the relationship between drug use and traffic crash severity in the Netherlands and showed no clear associations to verify the impacts of alcohol and illicit drug, on crash severities. An analysis of roadside surveys and crash data conducted by Zador (1991) showed that at a BAC of 0.05 or greater, the risk of involvement in an alcohol-related fatal crash increases significantly. Bédard et al. (2002) found a positive relationship between ages and fatal injuries, after controlling for other variables like gender and BAC. Around intersections where two or more roadways cross each other, vehicle turning and crossing movements have the potential for conflicts leading to severe crashes. Persaud et al. (2002) estimated crash prediction models for three and four-legged intersections in Toronto. Sayed and Rodriguez (1999) used the generalized linear models to estimate crash occurrence risks at urban unsignalized intersections and the model parameters were estimated using the Poisson error structure. Poch and Mannering (1996) developed a negative binomial model to identify rear-end crash risks at signalized and unsignalized intersections, and they found negative binomial regression models are suitable to model isolated intersection traffic and geometric factors. Retting et al. (2003) investigated vehicle crashes at stop sign-controlled intersections. Lau and May (1989) used data classification and regression tree techniques analysis to predict crashes at unsignalized intersections. Therefore, a broad range of variables were found to have impacts on crash severities either in alcohol-involved crashes or intersection-related crashes, including environmental and geometric features as well as driver characteristics.

In terms of statistical analysis techniques and modeling methodologies, researchers have proposed and developed various discrete choice models to analyze the significant factors for crash severity. Both ordered and unordered models have been developed to investigate injury severities in crashes. For instance, Neyens and Boyle (2007) used an ordered Logit model to predict the likelihood of severe injuries for distracted teenage drivers and their passengers (IIHS \& NHTSA 2006). Gray et al. (2008) analyzed injury severities of crashes involving young male drivers in Great Britain based on ordered Probit models. They identified specific crash characteristics that increase the likelihood of one of three categorical outcomes of crash severity: slight, serious, or fatal. Some other researchers, such as Duncan et al. (1998), Khattak (2001), Kockelman and Kweon (2002), O'Donnell and Connor (1996), Renski et al. (1999), and Yamamoto and Shankar (2004) also used ordered probability models to investigate crash severi- 
ties and the corresponding causal factors. However, various studies applied unordered models without accounting for the ordinal nature of injury data. For example, Ulfarsson and Mannering (2004) used the multinomial Logit model to predict the probability of four injury severity outcomes: no injury (property damage only), possible injury, evident injury, and fatal/disabling injury. Wang and Zhang (2011) established three multivariate binary Logit models of crash severities for the entire driver group, the teenage driver group (IIHS \& NHTSA 2006), and the adult driver group. Chang and Mannering (1999) accounted for the effects of large trucks and indicated its significant impact on the most severely injured occupants, by separately estimating nested Logit models for truck-involved crashes and for non-truckinvolved crashes. Islam and Mannering (2006) chose an unordered discrete outcome model to formulate crash severities in their study of driver aging and its effects on male and female single-vehicle crash injuries, stating that there is an inherent tradeoff made between recognizing the ordering of responses, potential biases in coefficient estimates, and losing flexibility in specification offered by unordered probability models. In this study, three multinomial Logit models are developed to identify significant causal factors in intersection-related traffic crashes for all drivers, alcohol-influenced drivers, and non-alcohol-influenced drivers. The data descriptions and model specifications and results are detailed subsequently as follows.

\section{Data Description}

Two-year New Mexico intersection-related traffic crash data were obtained from the New Mexico Department of Transportation (NMDOT) Traffic Safety Division (TSD) and the Division of Government Research (DGR) at the University of New Mexico (UNM) from 2010 to 2011. Three major datasets are included in this study: crash data, vehicle data, and driver data, which detail all the information regarding crash types, locations, severities, occurrence times, roadway geometric characteristics, weather conditions, vehicle characteristics, and driver demographic and behavior information. Special care was taken to screen out the incomplete and outlier data to enhance the data quality. For example, the records with incomplete or obviously incorrect information, such as driver ages entered as 0 or 5 , were removed from this study dataset. Eventually, a total of 49073 vehicle records are used for model development and estimation. The descriptive statistics for the variables are provided in Table 1. The data are divided into two groups based on the influence of alcohol indicated by the variable, Alcohol-influenced, shown in Table 1: alcohol-influenced drivers and non-alcohol-influenced drivers. In this study, drivers are classified as alcoholinfluenced if their BACs were greater than $0.0 \%$ for fatal crashes or they were evaluated by the reporting police officers onsite for injurious and no injurious crashes.

Table 1. Variable definitions and descriptions

\begin{tabular}{|c|c|c|c|c|c|c|c|c|c|}
\hline Variable description & \multicolumn{2}{|c|}{ No injury } & \multicolumn{2}{|c|}{ Possible injury } & \multicolumn{2}{|c|}{ Visible injury } & \multicolumn{2}{|c|}{$\begin{array}{l}\text { Incapacitating } \\
\text { injury/fatality }\end{array}$} & All \\
\hline \multicolumn{10}{|c|}{ Crash characteristics } \\
\hline Severity & 39947 & $81.4 \%$ & 7240 & $14.8 \%$ & 1283 & $2.6 \%$ & 603 & $1.2 \%$ & 49073 \\
\hline \multicolumn{10}{|l|}{ Day } \\
\hline Sunday & 3031 & $80.2 \%$ & 568 & $15.0 \%$ & 129 & $3.4 \%$ & 49 & $1.3 \%$ & 3777 \\
\hline Monday & 6126 & $81.6 \%$ & 1111 & $14.8 \%$ & 190 & $2.5 \%$ & 76 & $1.0 \%$ & 7503 \\
\hline Tuesday & 6377 & $81.1 \%$ & 1196 & $15.2 \%$ & 193 & $2.5 \%$ & 101 & $1.3 \%$ & 7867 \\
\hline Wednesday & 6363 & $81.2 \%$ & 1181 & $15.1 \%$ & 197 & $2.5 \%$ & 95 & $1.2 \%$ & 7836 \\
\hline Thursday & 6435 & $82.3 \%$ & 1113 & $14.2 \%$ & 174 & $2.2 \%$ & 94 & $1.2 \%$ & 7816 \\
\hline Friday & 7289 & $81.8 \%$ & 1289 & $14.5 \%$ & 223 & $2.5 \%$ & 108 & $1.2 \%$ & 8909 \\
\hline Saturday & 4326 & $80.6 \%$ & 782 & $14.6 \%$ & 177 & $3.3 \%$ & 80 & $1.5 \%$ & 5365 \\
\hline \multicolumn{10}{|c|}{ Time Period } \\
\hline Morning & 14655 & $81.3 \%$ & 2666 & $14.8 \%$ & 436 & $2.4 \%$ & 259 & $1.4 \%$ & 18016 \\
\hline Afternoon & 13927 & $81.6 \%$ & 2482 & $14.5 \%$ & 464 & $2.7 \%$ & 197 & $1.2 \%$ & 17070 \\
\hline Evening & 9276 & $81.7 \%$ & 1669 & $14.7 \%$ & 292 & $2.6 \%$ & 112 & $1.0 \%$ & 11349 \\
\hline Night & 2089 & $79.2 \%$ & 423 & $16.0 \%$ & 91 & $3.4 \%$ & 35 & $1.3 \%$ & 2638 \\
\hline \multicolumn{10}{|l|}{ Crash Analysis } \\
\hline Motorcycle involved & 481 & $90.2 \%$ & 29 & $5.4 \%$ & 15 & $2.8 \%$ & 8 & $1.5 \%$ & 533 \\
\hline Truck involved & 835 & $87.9 \%$ & 74 & $7.8 \%$ & 23 & $2.4 \%$ & 18 & $1.9 \%$ & 950 \\
\hline \multicolumn{10}{|c|}{ Environment characteristics } \\
\hline \multicolumn{10}{|l|}{ Weather } \\
\hline Clear & 37226 & $81.2 \%$ & 6792 & $14.8 \%$ & 1219 & $2.7 \%$ & 580 & $1.3 \%$ & 45817 \\
\hline Rain & 1382 & $81.8 \%$ & 256 & $15.2 \%$ & 40 & $2.4 \%$ & 11 & $0.7 \%$ & 1689 \\
\hline Snow & 756 & $89.4 \%$ & 84 & $9.9 \%$ & 5 & $0.6 \%$ & 1 & $0.1 \%$ & 846 \\
\hline
\end{tabular}


Continue of Table 1

\begin{tabular}{|c|c|c|c|c|c|c|c|c|c|}
\hline \multirow{2}{*}{$\begin{array}{l}\text { Variable description } \\
\text { Fog }\end{array}$} & \multicolumn{2}{|c|}{ No injury } & \multicolumn{2}{|c|}{ Possible injury } & \multicolumn{2}{|c|}{ Visible injury } & \multicolumn{2}{|c|}{$\begin{array}{l}\text { Incapacitating } \\
\text { injury/fatality }\end{array}$} & \multirow{2}{*}{$\begin{array}{c}\text { All } \\
60\end{array}$} \\
\hline & 45 & $75.0 \%$ & 11 & $18.3 \%$ & 2 & $3.3 \%$ & 2 & $3.3 \%$ & \\
\hline Dust & 36 & $81.8 \%$ & 7 & $15.9 \%$ & 0 & $0.0 \%$ & 1 & $2.3 \%$ & 44 \\
\hline Wind & 317 & $80.5 \%$ & 60 & $15.2 \%$ & 11 & $2.8 \%$ & 6 & $1.5 \%$ & 394 \\
\hline Other & 185 & $83.0 \%$ & 30 & $13.5 \%$ & 6 & $2.7 \%$ & 2 & $0.9 \%$ & 223 \\
\hline \multicolumn{10}{|l|}{ Light } \\
\hline Dark & 5300 & $80.4 \%$ & 1024 & $15.5 \%$ & 181 & $2.7 \%$ & 84 & $1.3 \%$ & 6589 \\
\hline Dawn or dust & 1301 & $81.4 \%$ & 228 & $14.5 \%$ & 49 & $2.9 \%$ & 17 & $1.1 \%$ & 1595 \\
\hline Daylight & 33346 & $81.6 \%$ & 5988 & $14.6 \%$ & 1053 & $2.6 \%$ & 502 & $1.2 \%$ & 40889 \\
\hline \multicolumn{10}{|c|}{ Geometry characteristics } \\
\hline Rural & 1810 & $75.2 \%$ & 363 & $15.1 \%$ & 142 & $5.9 \%$ & 91 & $3.8 \%$ & 2406 \\
\hline \multicolumn{10}{|l|}{ Population group } \\
\hline Population group $1(<25000)$ & 9671 & $81.3 \%$ & 1661 & $14.0 \%$ & 378 & $3.2 \%$ & 190 & $1.6 \%$ & 11900 \\
\hline Population group $2(25000-50000)$ & 13001 & $82.6 \%$ & 2216 & $14.1 \%$ & 372 & $2.4 \%$ & 156 & $1.0 \%$ & 15745 \\
\hline Population group $3(>50000)$ & 17275 & $80.6 \%$ & 3363 & $15.7 \%$ & 533 & $2.5 \%$ & 257 & $1.2 \%$ & 21428 \\
\hline \multicolumn{10}{|c|}{ Road characteristics } \\
\hline Curve & 2051 & $84.7 \%$ & 292 & $12.1 \%$ & 66 & $2.7 \%$ & 13 & $0.5 \%$ & 2422 \\
\hline \multicolumn{10}{|l|}{ Grade } \\
\hline Level & 35253 & $81.4 \%$ & 6373 & $14.7 \%$ & 1142 & $2.6 \%$ & 525 & $1.2 \%$ & 43293 \\
\hline Hillcrest & 924 & $84.2 \%$ & 147 & $13.4 \%$ & 18 & $1.6 \%$ & 8 & $0.7 \%$ & 1097 \\
\hline On grade & 3584 & $80.3 \%$ & 690 & $15.5 \%$ & 120 & $2.7 \%$ & 67 & $1.5 \%$ & 4461 \\
\hline Dip & 95 & $81.9 \%$ & 18 & $15.5 \%$ & 2 & $1.7 \%$ & 1 & $0.9 \%$ & 116 \\
\hline Other & 91 & $85.8 \%$ & 12 & $11.3 \%$ & 1 & $0.9 \%$ & 2 & $1.9 \%$ & 106 \\
\hline \multicolumn{10}{|c|}{ Road surface condition } \\
\hline Dry & 36856 & $81.2 \%$ & 6743 & $14.9 \%$ & 1210 & $2.7 \%$ & 572 & $1.3 \%$ & 45381 \\
\hline Wet & 2087 & $81.1 \%$ & 405 & $15.7 \%$ & 56 & $2.2 \%$ & 26 & $1.0 \%$ & 2574 \\
\hline Snow & 426 & $90.6 \%$ & 39 & $8.3 \%$ & 4 & $0.9 \%$ & 1 & $0.2 \%$ & 470 \\
\hline Ice & 389 & $92.6 \%$ & 26 & $6.2 \%$ & 3 & $0.7 \%$ & 2 & $0.5 \%$ & 420 \\
\hline Other & 189 & $82.9 \%$ & 27 & $11.8 \%$ & 10 & $4.4 \%$ & 2 & $0.9 \%$ & 228 \\
\hline Road surface paving & 151 & $86.8 \%$ & 16 & $9.2 \%$ & 4 & $2.3 \%$ & 3 & $1.7 \%$ & 174 \\
\hline \multicolumn{10}{|c|}{ Traffic control } \\
\hline No control & 7246 & $78.9 \%$ & 1487 & $16.2 \%$ & 316 & $3.4 \%$ & 145 & $1.5 \%$ & 9194 \\
\hline Stop sign & 8558 & $85.1 \%$ & 1135 & $11.3 \%$ & 250 & $2.5 \%$ & 111 & $1.1 \%$ & 10054 \\
\hline Signal control & 24094 & $80.9 \%$ & 4614 & $15.5 \%$ & 716 & $2.4 \%$ & 346 & $1.2 \%$ & 29770 \\
\hline Railroad gate & 49 & $89.1 \%$ & 4 & $7.3 \%$ & 1 & $1.8 \%$ & 1 & $1.8 \%$ & 55 \\
\hline \multicolumn{10}{|l|}{ Number of lanes } \\
\hline One lane & 10541 & $82.6 \%$ & 1703 & $13.3 \%$ & 357 & $2.8 \%$ & 161 & $1.3 \%$ & 12762 \\
\hline Two lanes & 15821 & $81.4 \%$ & 2875 & $14.8 \%$ & 512 & $2.6 \%$ & 236 & $1.2 \%$ & 19444 \\
\hline Multi lanes & 13585 & $80.5 \%$ & 2662 & $15.8 \%$ & 414 & $2.5 \%$ & 206 & $1.2 \%$ & 16867 \\
\hline \multicolumn{10}{|c|}{ Vehicle characteristics } \\
\hline \multicolumn{10}{|l|}{ Number of vehicle } \\
\hline Single vehicle & 87 & $73.1 \%$ & 12 & $10.1 \%$ & 14 & $11.8 \%$ & 6 & $5.0 \%$ & 119 \\
\hline Two vehicles & 35607 & $82.4 \%$ & 6041 & $14.0 \%$ & 1082 & $2.5 \%$ & 498 & $1.2 \%$ & 43228 \\
\hline Multiple vehicles & 4253 & $74.3 \%$ & 1187 & $20.7 \%$ & 187 & $3.3 \%$ & 99 & $1.7 \%$ & 5726 \\
\hline \multicolumn{10}{|c|}{ Vehicle type } \\
\hline Passenger car & 21232 & $79.0 \%$ & 4510 & $16.8 \%$ & 773 & $2.9 \%$ & 368 & $1.4 \%$ & 26883 \\
\hline Pick-up & 9817 & $85.8 \%$ & 1267 & $11.1 \%$ & 254 & $2.2 \%$ & 106 & $0.9 \%$ & 11444 \\
\hline Tractor & 463 & $96.9 \%$ & 12 & $2.5 \%$ & 2 & $0.4 \%$ & 1 & $0.2 \%$ & 478 \\
\hline Bus & 222 & $94.1 \%$ & 14 & $5.9 \%$ & 0 & $0.0 \%$ & 0 & $0.0 \%$ & 236 \\
\hline Van & 8213 & $81.9 \%$ & 1437 & $14.3 \%$ & 254 & $2.5 \%$ & 128 & $1.3 \%$ & 10032 \\
\hline
\end{tabular}


End of Table 1

\begin{tabular}{|c|c|c|c|c|c|c|c|c|c|}
\hline Variable description & \multicolumn{2}{|c|}{ No injury } & \multicolumn{2}{|c|}{ Possible injury } & \multicolumn{2}{|c|}{ Visible injury } & \multicolumn{2}{|c|}{$\begin{array}{l}\text { Incapacitating } \\
\text { injury/fatality }\end{array}$} & All \\
\hline \multicolumn{10}{|c|}{ Driver characteristics } \\
\hline Seatbelt & 39819 & $81.6 \%$ & 7203 & $14.8 \%$ & 1226 & $2.5 \%$ & 563 & $1.2 \%$ & 48811 \\
\hline Alcohol-influenced & 474 & $74.3 \%$ & 73 & $11.4 \%$ & 61 & $9.6 \%$ & 30 & $4.7 \%$ & 638 \\
\hline Female & 18502 & $77.0 \%$ & 4523 & $18.8 \%$ & 657 & $2.7 \%$ & 345 & $1.4 \%$ & 24027 \\
\hline \multicolumn{10}{|c|}{ Driver actions } \\
\hline Slow & 1060 & $85.8 \%$ & 158 & $12.8 \%$ & 13 & $1.1 \%$ & 4 & $0.3 \%$ & 1235 \\
\hline Left turn & 6398 & $81.5 \%$ & 1072 & $13.7 \%$ & 256 & $3.3 \%$ & 121 & $1.5 \%$ & 7847 \\
\hline Right turn & 2961 & $91.3 \%$ & 236 & $7.3 \%$ & 32 & $1.0 \%$ & 15 & $0.5 \%$ & 3244 \\
\hline Overtaking & 178 & $88.1 \%$ & 16 & $7.9 \%$ & 6 & $3.0 \%$ & 2 & $1.0 \%$ & 202 \\
\hline Straight & 28913 & $80.1 \%$ & 5748 & $15.9 \%$ & 971 & $2.7 \%$ & 460 & $1.3 \%$ & 36092 \\
\hline U-turn & 79 & $88.8 \%$ & 5 & $5.6 \%$ & 4 & $4.5 \%$ & 1 & $1.1 \%$ & 89 \\
\hline Backing & 358 & $98.4 \%$ & 5 & $1.4 \%$ & 1 & $0.3 \%$ & 0 & $0.0 \%$ & 364 \\
\hline \multicolumn{10}{|c|}{ Driver age } \\
\hline 16 to 20 years & 5878 & $83.3 \%$ & 885 & $12.5 \%$ & 219 & $3.1 \%$ & 74 & $1.0 \%$ & 7056 \\
\hline 21 to 34 years & 12950 & $82.4 \%$ & 2203 & $14.0 \%$ & 408 & $2.6 \%$ & 158 & $1.0 \%$ & 15719 \\
\hline 35 to 44 years & 6352 & $80.9 \%$ & 1242 & $15.8 \%$ & 156 & $2.0 \%$ & 102 & $1.3 \%$ & 7852 \\
\hline 45 to 54 years & 6076 & $80.3 \%$ & 1254 & $16.6 \%$ & 154 & $2.0 \%$ & 82 & $1.1 \%$ & 7566 \\
\hline 55 to 64 years & 4546 & $78.8 \%$ & 967 & $16.8 \%$ & 161 & $2.8 \%$ & 93 & $1.6 \%$ & 5767 \\
\hline 65 years or older & 4145 & $81.1 \%$ & 689 & $13.5 \%$ & 185 & $3.6 \%$ & 94 & $1.8 \%$ & 5113 \\
\hline
\end{tabular}

Each record is detailed at vehicle levels, which contain all information about individual vehicles and drivers in crashes. The variable, Severity, is used to classify driver's injury severities into four categories: No injury, Possible injury, Visible injury, and Incapacitating injury/fatality. Table 1 shows the percentage distribution across driver injury severity categories.

Basic statistical analyzes and graphic visualizations are conducted to interpret the characteristics for drivers under the influence of alcohol and provide a general overview of alcohol related driver injury severities around intersections in New Mexico. Figure shows the driver's injury severity classification tree in intersectionrelated crashes. After screening out uncompleted and obviously uncorrected records, the data records used in this study contain 49073 drivers involved in crashes occurring around intersections in New Mexico from 2010 to 2011 . Although only $1.3 \%$ of the total drivers are found to be influenced by alcohol in these crashes, more severe driver injury outcomes are observed in this category. Thirty alcohol-influenced drivers are identified with incapacitating or fatal injury in the intersection-related crashes accounting for $4.7 \%$ of the total alcohol-influenced drivers involved in crashes, which is significantly higher than $1.2 \%$, the proportion of driver incapacitating or fatal injuries to the total non-alcoholinfluenced drivers. The driver visible injury data demonstrate the similar pattern. The proportion of alcohol-influenced drivers suffering visible injury is about $9.6 \%$, which is also much higher than its equivalent of non-alcohol-influenced drivers, $2.5 \%$. These data indicate although the number of alcohol-influenced drivers accounts for a small proportion of the total number of drivers in intersection-related crashes, they suffer more severe injuries and fatalities, which verified the necessity to investigate the unique characteristics, associated with alcohol-influenced drivers and significant contributing factors to driver injury severities.

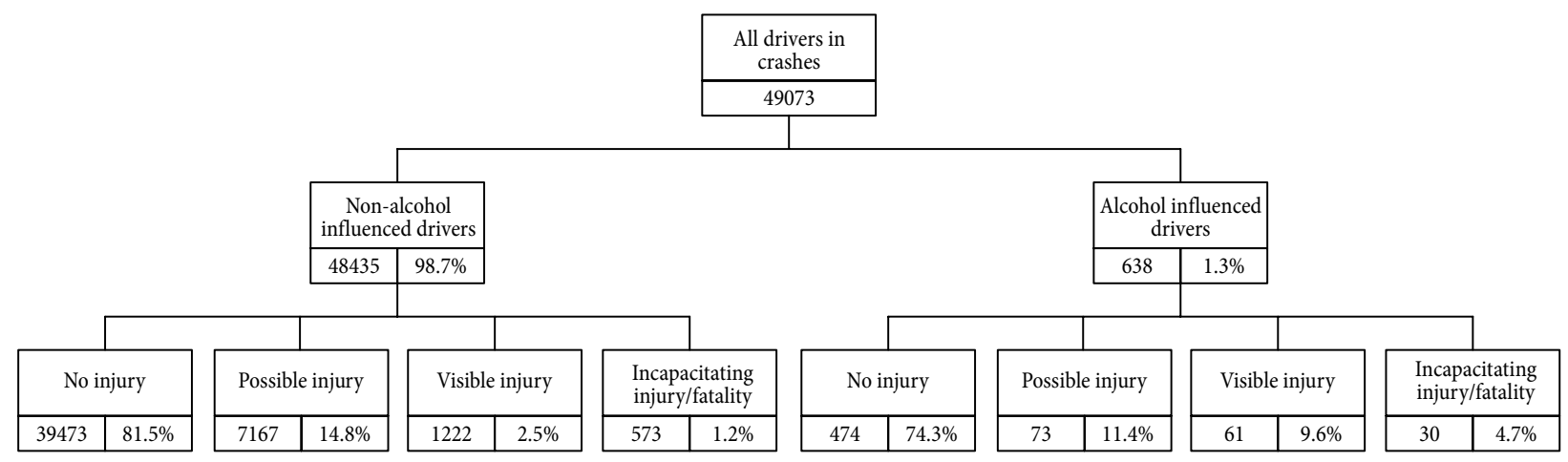

Fig. Intersection-related driver injury severity classification tree 


\section{Methodology}

In this study, according to data sample size, data attributes, and NMDOT standards, four injury severity categories are used: No injury, Possible injury, Visible injury and Incapacitating injury/fatality. Considering that four discrete severity outcomes are specified, many statistical modeling approaches can be used, such as ordered discrete probability models, which can explicitly recognize the monotonic change pattern in crash severities. Many previous studies were conducted using such modeling approaches for crash severity investigations (Abdel-Aty, Radwan 2000; Kockelman, Kweon 2002). However, ordered probability models may not be suitable for nonmonotonic-changing severity data due to their strong restrictions on the linear relationship between explanatory variables and independent outcomes. For example, the steep roadway grade may increase crash severities when its absolute value is small or moderate. When its absolute value continuously increases beyond a certain range, crash severities tend to decrease due to the facts that drivers will travel much slower and pay more attention to handle abrupt grade changes in these situations. The other illustrative example could be the usage of airbag. If an airbag is deployed, the probability of severe injury and fatality could decline but it may increase the likelihood of minor injury of drivers resulting from airbag activation. The application restriction of ordered probability models indicates that changing explanatory variables shall either increase or decrease crash severities in a monotonic manner across all the possible outcomes, which is not always supported by the severity data. Therefore, a more commonly used unordered discrete modeling approach, multinomial Logit model, is adopted in this study.

\subsection{Driver's Injury Severity Modeling}

To formulate the probability relationship between driver injury severity and its causal factors, the discrete choice model, multinomial Logit model, is used in this study. Assume $S_{i n}$, the utility function that determines the probability of driver $n$ suffering severity outcome $i$ in a crash, is defined as follows:

$$
S_{i n}=\boldsymbol{\beta}_{i} \boldsymbol{X}_{\text {in }}+\varepsilon_{i n},
$$

where: $\boldsymbol{X}_{i n}$ is a vector of exogenous explanatory variables associated with driver $n$ to determine injury severity $i$; $\boldsymbol{\beta}_{i}$ is a vector of estimated coefficients; $\varepsilon_{i n}$ is the random utility component and represents these unobservable influences on severity outcomes. If $\varepsilon_{\text {in }}$ is assumed to be Generalized Extreme Value (GEV) distributed, then a multinomial Logit model can be derived as (Train 2009):

$$
P_{\text {in }}=\frac{\exp \left(\boldsymbol{\beta}_{i} \boldsymbol{X}_{\text {in }}\right)}{\sum_{\forall I} \exp \left(\boldsymbol{\beta}_{i} \boldsymbol{X}_{\text {in }}\right)},
$$

where: $P_{i n}$ is the probability of driver $n$ suffering injury outcome $i$ in a crash, and $I$ is the choice set of possible injury severity outcomes. In this study, driver injury severity outcomes are classified into four categories: no injury, possible injury, visible injury and incapacitating injury/fatality. Three multinomial Logit models were established for the entire driver group, the alcohol-influenced driver group, and the non-alcohol-influenced driver group, respectively.

\subsection{Elasticity Analysis}

Due to the limitation of estimated coefficients in measuring the magnitude of the impacts of significant variables on driver injury severity probabilities, elasticity analysis is conducted for three models in this study. The elasticities of variables for each injury category are calculated in this study in order to assess the effect of variables on driver injury outcomes when the values of variables change one unit. The direct elasticity of the variable $X_{\text {ink }}$ can be calculated as follows to quantify its corresponding percent effect on severity outcome probabilities when its value changes by $1 \%$ :

$$
E_{X_{i n k}}^{P_{i n}}=\frac{\partial P_{i n}}{\partial X_{i n k}} \frac{X_{i n k}}{P_{i n}},
$$

where: $X_{\text {ink }}$ is the value of the $k$ th variable associated with driver $n$ in the utility function of injury outcome $i$. For the indicator variables which take the values of 0 or 1 only, pseudo-elasticity is used instead of direct elasticity as follows (Kim et al. 2007):

$$
E_{X_{\text {ink }}}^{P_{P_{n}}}=\exp \left(\beta_{\text {ink }}\right)\left(\frac{\sum \exp \left(\boldsymbol{\beta}_{\boldsymbol{i}^{\prime}} \cdot \boldsymbol{X}_{\text {in }}\right)}{\sum \exp \left(\Delta\left(\boldsymbol{\beta}_{\boldsymbol{i}^{\prime}} \cdot \boldsymbol{X}_{\text {in }}\right)\right)}-1\right) \cdot 100,
$$

where: $\beta_{i n k}$ is the estimated coefficient of the variable $X_{i n k}, \Delta\left(\boldsymbol{\beta}_{i^{\prime}} \cdot \boldsymbol{X}_{i n}\right)$ is the value of the function determining injury severity with $X_{i n k}$ set to 0 , and $\boldsymbol{\beta}_{\boldsymbol{i}^{\prime}} \cdot \boldsymbol{X}_{\text {in }}$ is the value with $X_{i n k}$ set to $1 . E_{X_{i n k}}^{P_{i n}}$ measures the percentage change in the severity outcome probability for driver $n$, $P_{i n}$, when the $k$ th indicator variable, $X_{i n k}$, switches from 0 to 1 (Washington et al. 2003). In this study, the average pseudo elasticity for a specific variable across all observations is calculated in order to quantify the magnitude of its impacts on specific severity outcomes. The detailed model specifications and estimation results are described in next section.

\section{Model Estimation Results}

In order to identify and analyze the significant contributing factors influencing driver injury severities, three multinomial Logit models were developed for different driver groups: all drivers, alcohol-influenced drivers, and non-alcohol-influenced drivers, respectively. Elasticity analysis is conducted to quantitatively interpret the coefficients estimated in those models and their impacts on severity outcomes. These models were estimated using the maximum likelihood estimation method, and the statistical software package, Python BIOGEME (Python BIerlaire Optimization toolbox for GEV Model Estimation) was used for model parameter estimation and elasticity analysis. Driver injury severities are classified into four categories: No Injury, Possible Injury, Visible Injury and Incapacitating Injury/Fatality. The coefficients of the 
significant variables specified in these models are shown in Tables 2, 4, and 6, respectively, including coefficient estimates (Coef.), standard errors (Std.) t-statistics (Tratio), and significance levels for the test of significant difference of a coefficient from zero (P-value). The average pseudo elasticities of every variable captured in these models across injury severity categories are shown in Tables 3, 5 and 7. The model estimation results and discussions are provided as follows.

\subsection{All Driver's Model}

In order to illustrate the overall impacts of significant contributing factors on driver injury severities in an intersection-related crash, a multinomial Logit model is developed for the entire driver group. As shown in Table 2, the likelihood ratio index, $\rho^{2}$, is equal to 0.58 , which indicates the reasonable goodness-of-fit of the proposed model to the data. Using the injury severity category, Incapacitating injury/fatality, as the estimation base, the constants specific to No injury, Possible injury and Non-incapacitating injury, are estimated as $2.87,2.40$ and 0.8 , respectively, at the significant level of $p=0.01$. These three constants indicate that drivers are more likely to get involved in a crash of no injury or slight injury but less likely to suffer severely or fatally injuries in intersection-related crashes without considering any other factor given a crash occurrence. In the proposed model, the constant specific to Incapacitating injury/fatality can be regarded as 0 , and the values of the constants illustrate the magnitudes of the relative likelihood of potential outcomes.

The coefficients of the variable, Alcohol-influenced, specific to No injury and Possible injury are equal to -1.45 and -1.51 , which are significantly different from 0 at the $p=0.01$ significant level, indicating Alcoholinfluenced is a significant variable influencing driver injury severities. Relative to non-alcohol-influenced drivers (the value of variable, Alcohol-influenced, is equal to 0) in intersection-related crashes, the probabilities of visible injury and incapacitating injury/fatality for alcohol-influenced drivers (the value of variable, Alcohol-influenced, is equal to 1) increased by $284.0 \%$. This result implies that alcohol-influenced drivers have a considerably high probability of suffering more severe injurious and fatal outcomes, which is consistent with the previous studies (Traynor 2005; Zador 1991). The significant impacts of the variable, Alcohol-influenced, on driver injury severities further underscore the necessity separating entire driver population into different groups: alcohol-influenced drivers and non-alcohol-influenced drivers for their specific attribute investigations.

The variable, Rural, is an indicator variable showing whether the crashes occurred in rural areas or not. It has a significant impact on driver injury severities, and its elasticities specific to Possible injury, Visible injury, and Incapacitating injury/fatality are 12.2\%, 129.1\% and $227.1 \%$, respectively. These results indicate that relative to driver injuries in intersection-related crashes in urban areas, the probabilities of having drivers possibly, visibly, and severely/fatally injured increased by $12.2 \%$,
$129.1 \%$, and $227.1 \%$ for rural crashes, respectively. This reflects the higher severity levels of driver injuries in rural crashes, which is consistent with the data provided by NMDOT (2010) that about $20 \%$ of the total crashes occurred in rural areas but they accounted for $65 \%$ of total driver fatalities. In terms of traffic control modes, two variables, Stop sign and Signal control are identified to be significant. Their coefficients and elasticities specific to Possible injury, Visible injury and Incapacitating injury/fatality, show that these two types of traffic control modes can significantly improve safety performance at intersections. Relative to other control modes including no control, no passing zone, and railroad gate, stop sign control increases the probability of having a crash of property damage only by $7.5 \%$ given crash occurrence around intersections. The likelihoods of drivers suffering possible injuries, and visible or more severe injuries decrease by $4 \%$ and $27.1 \%$ at signal-controlled intersections. These findings further verify that stop sign control and signal control can significantly improve safety performance at intersections and reduce the probability of drivers being severely and fatally injured

The variable, Multiple vehicles, represents that the number of vehicles involved in a crash is greater than two, and its positive elasticity specific to No injury, $-9.7 \%$, show that relative to single-vehicle and two-vehicle crashes, there is an $9.7 \%$ decrease in the likelihood of drivers being no injured in multi-vehicle crashes. Since single-vehicle crashes only account for $0.2 \%$ of the total crashes, it is safe to draw a conclusion that the probability of having injurious and fatal crashes would increase significantly when the number of vehicle involved in crashes increases to three or more.

As can be expected, using a seat belt can significantly decrease the probabilities of drivers suffering injury and fatality. The elasticity of the variable, Seatbelt, specific to No injury is $69.6 \%$, indicating that relative to non-seat belt usage, using a seat belt may cause a $69.6 \%$ increase in the probability of drivers being no injured in intersection-related crashes. These findings are well supported by the previous studies that unrestrained drivers have a higher likelihood to suffer more severe injury or fatality (Savolainen, Mannering 2007; Shankar, Mannering 1996).

Interestingly, the variable, Female, was found to have non-monotonic impacts on driver injury outcomes. Relative to male drivers, there is a $27.5 \%$ increase in the likelihood of visible, and incapacitating and fatal injury for female ones when getting involved in crashes around intersections. The probability of having them possibly injured increases by $75.6 \%$, but it decreases by $10.6 \%$ for female drivers being no injured relative to male drivers. This implies that female drivers are more likely to get possible, minor injured in crashes but less likely to be severely or no injured. These interesting results reflect the complex impacts of female driver behavior and demographics on driver injury outcomes. In terms of driver actions, the variable, Left turn, is also found its non-monotonic impacts on driver injury outcomes with the positive elasticities specific to Visible injury 
and Incapacitating injury/fatality and the negative elasticities specific to Possible injury and No injury. When a crash occurs due to vehicle left-turn movements, the probabilities of drivers being visibly, evidently and fatally injured increase by $35.3 \%$, being possibly injured decrease by $3.7 \%$, and being no injured decrease by $0.9 \%$ compared with other driver actions, such as right turning, slowing, overtaking, U-turning, backing, and going straight. Such mixed results are attributed to the facts that drivers may be more cautious and prepare for unfavorable driving conditions when making left-turn movements around an intersection to reduce the potential of severe crashes from possible injury to no injury. However, vehicle collisions due to left-turn movements are normally characterized by head-on and other types of severe crashes which are also impacted by through traffic at relatively high speeds on opposing approaches. The driver age variable, 65 years or older, represents the group of drivers who are more than 65 years old. Its elasticities specific to Visible injury and Incapacitating inju$r y /$ fatality indicate that relative to younger driver groups, there is a $55.6 \%$ increase in the likelihood of being vis-

Table 2. Driver's injury severity model estimation for all drivers

\begin{tabular}{|l|c|c|c|c|}
\hline \multicolumn{1}{|c|}{ Variable $^{\mathrm{a}}$} & Coef. $^{\mathrm{b}}$ & Std. $^{\mathrm{c}}$ & $T$-ratio & $P$-value \\
\hline Constant(N) & 2.87 & 0.14 & 20.47 & $0.00\left(^{* *}\right)$ \\
\hline Constant(P) & 2.40 & 0.07 & 36.63 & $0.00\left(^{* *}\right)$ \\
\hline Constant(I) & 0.80 & 0.05 & 15.06 & $0.00\left(^{* *}\right)$ \\
\hline Rural(N) & -1.28 & 0.12 & -10.84 & $0.00\left(^{* *}\right)$ \\
\hline Rural(P) & -1.07 & 0.13 & -8.40 & $0.00\left(^{* *}\right)$ \\
\hline Rural(I) & -0.36 & 0.14 & -2.46 & $\left.0.01^{*}\right)$ \\
\hline Stop Sign(N) & 0.43 & 0.04 & 11.33 & $0.00\left(^{* *}\right)$ \\
\hline Signal control(N) & 0.34 & 0.05 & 6.62 & $0.00\left(^{* *}\right)$ \\
\hline Signal control(P) & 0.28 & 0.05 & 5.17 & $0.00\left(^{* *}\right)$ \\
\hline Multiple vehicles(N) & -0.48 & 0.03 & -14.16 & $0.00\left(^{* *}\right)$ \\
\hline Seatbelt(N) & 1.56 & 0.13 & 12.29 & $0.00\left(^{* *}\right)$ \\
\hline Alcohol-influenced(N) & -1.45 & 0.12 & -11.93 & $0.00\left(^{* *}\right)$ \\
\hline Alcohol-influenced(P) & -1.51 & 0.16 & -9.35 & $0.00\left(^{* *}\right)$ \\
\hline Female(N) & -0.36 & 0.05 & -7.41 & $0.00\left(^{* *}\right)$ \\
\hline Female(P) & 0.32 & 0.05 & 6.06 & $0.00\left(^{* *}\right)$ \\
\hline Left turn(N) & -0.31 & 0.06 & -5.25 & $0.00\left(^{* *}\right)$ \\
\hline Left turn(P) & -0.34 & 0.07 & -5.11 & $0.00\left(^{* *}\right)$ \\
\hline 65 years or older(N) & -0.46 & 0.07 & -6.76 & $0.00\left(^{* *}\right)$ \\
\hline 65 years or older(P) & -0.49 & 0.08 & -6.39 & $0.00\left(^{* *}\right)$ \\
\hline Log likelihood with constants only & -68030 & \\
\hline Log likelihood at convergence & & -28628 & \\
\hline Likelihood ratio index, $\rho^{2}$ & & 0.58 & \\
\hline
\end{tabular}

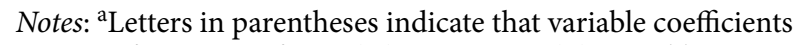
are significant specific to (N) No injury, (P) Possible injury, (V) Visible injury and (I/F) Incapacitating injury/fatality; The constants specific to the incapacitating injury/fatality outcome has been normalized to zero; ${ }^{b}$ Estimated Coefficient; ${ }^{c}$ Standard Error; The asterisk represents the level of significance: ${ }^{* *}$ for $>99 \%$ and ${ }^{\star}$ for $>95 \%$.
Table 3. Average variable pseudo elasticity for all driver's model (\%)

\begin{tabular}{|l|c|c|c|c|}
\hline \multicolumn{1}{|c|}{ Variable } & $\begin{array}{c}\text { No } \\
\text { injury }\end{array}$ & $\begin{array}{c}\text { Possible } \\
\text { injury }\end{array}$ & $\begin{array}{c}\text { Visible } \\
\text { injury }\end{array}$ & $\begin{array}{c}\text { Incapacitating } \\
\text { injury/fatality }\end{array}$ \\
\hline Rural & -9.1 & 12.2 & 129.1 & 227.1 \\
\hline Stop sign & 7.5 & -29.7 & -29.7 & -29.7 \\
\hline Signal control & 2.3 & -4.0 & -27.1 & -27.1 \\
\hline $\begin{array}{l}\text { Multiple } \\
\text { vehicles }\end{array}$ & -9.7 & 45.4 & 45.4 & 45.4 \\
\hline Seatbelt & 69.6 & -64.4 & -64.4 & -64.4 \\
\hline $\begin{array}{l}\text { Alcohol- } \\
\text { influenced }\end{array}$ & -9.9 & -15.2 & 284.0 & 284.0 \\
\hline Female & -10.6 & 75.6 & 27.5 & 27.5 \\
\hline Left turn & -0.9 & -3.7 & 35.6 & 35.6 \\
\hline $\begin{array}{l}65 \text { years or } \\
\text { older }\end{array}$ & -1.6 & -4.8 & 55.6 & 55.6 \\
\hline
\end{tabular}

ibly, severely, and fatally injured for drivers of 65 years or older. The likelihood for them to experience crashes of property damage only decreases by $1.6 \%$. This result indicates that drivers of 65 years or older are more likely to suffer evident and severe injury but less likely to get involved in intersection-related crashes of possible injury. Due to lengthened perception and reaction time needed for aging drivers, they are more likely to get involved in severe crashes. Meanwhile, they may be more cautious to increase the probability of being no injured. These findings are helpful to better understand the nonmonotonic impacts of the contributing factors, Female, Left turn, and 65 years or older for developing effective intersection-related crash safety improvement plans.

\subsection{Non-Alcohol-Influenced Driver's Model}

Table 4 presents the model estimation results for nonalcohol-influenced drivers. The likelihood ratio index, $\rho^{2}$, is 0.58 , showing the overall model goodness-of-fit is acceptable. Since non-alcohol-influenced drivers account for the majority of the crash record data used in this study, similar model specifications are achieved for the non-alcohol-influenced driver's model. However, as shown in Table 4, one additional variable, Passenger car, is found significant for the non-alcohol-influenced driving crashes at the level of $p=0.01$, which illustrates the impacts of vehicle types on driver injury outcome for non-alcohol-influenced drivers in intersection-related crashes. As can be expected, relative to drivers of the other vehicle types (the value of variable, Passenger car, is zero) including pickups, tractors, buses, and vans, passenger car drivers are vulnerable in intersection-related crashes. They are more likely to suffer possible and severe injury by $26.1 \%$ in crashes around intersections compared to others according to its pseudo elasticities shown in Table 5. This result is consistent with the conclusions of the previous studies (Huang et al. 2008; Khorashadi et al. 2005). Compared with model parameter interpretations for the all driver's model, similar analyzes can be conducted for the other variables in this nonalcohol-influenced driver's model. 
Table 4. Driver's injury severity model estimation for nonalcohol-influenced drivers

\begin{tabular}{|l|c|c|c|c|}
\hline \multicolumn{1}{|c|}{ Variable $^{\mathrm{a}}$} & Coef. $^{\mathrm{b}}$ & Std. $^{\mathrm{c}}$ & $T$-ratio & $P$-value \\
\hline Constant(N) & 3.07 & 0.15 & 20.64 & $\left.0.00^{(*}\right)$ \\
\hline Constant(P) & 2.40 & 0.07 & 36.14 & $0.00\left(^{* *}\right)$ \\
\hline Constant(I) & 0.80 & 0.05 & 14.77 & $0.00\left(^{* *}\right)$ \\
\hline Rural(N) & -1.33 & 0.12 & -10.87 & $0.00\left(^{* *}\right)$ \\
\hline Rural(P) & -1.09 & 0.13 & -8.31 & $0.00\left(^{* *}\right)$ \\
\hline Rural(I) & -0.37 & 0.15 & -2.44 & $0.01\left(^{*}\right)$ \\
\hline Stop sign(N) & 0.43 & 0.04 & 11.35 & $0.00\left(^{* *}\right)$ \\
\hline Signal control(N) & 0.34 & 0.05 & 6.46 & $0.00\left(^{* *}\right)$ \\
\hline Signal control(P) & 0.27 & 0.05 & 4.96 & $0.00\left(^{* *}\right)$ \\
\hline Multiple vehicles(N) & -0.48 & 0.03 & -14.10 & $0.00\left(^{* *}\right)$ \\
\hline Seatbelt(N) & 1.51 & 0.14 & 11.11 & $0.00\left(^{* *}\right)$ \\
\hline Passenger car(N) & -0.28 & 0.02 & -11.49 & $0.00\left(^{* *}\right)$ \\
\hline Female(N) & -0.31 & 0.05 & -6.27 & $0.00\left(^{* *}\right)$ \\
\hline Female(P) & 0.32 & 0.05 & 6.03 & $0.00\left(^{* *}\right)$ \\
\hline Left turn(N) & -0.32 & 0.06 & -5.26 & $0.00\left(^{* *}\right)$ \\
\hline Left turn(P) & -0.36 & 0.07 & -5.22 & $0.00\left(^{* *}\right)$ \\
\hline 65 years or older(N) & -0.45 & 0.07 & -6.53 & $0.00\left(^{* *}\right)$ \\
\hline 65 years or older(P) & -0.49 & 0.08 & -6.34 & $0.00\left(^{* *}\right)$ \\
\hline Log likelihood with constants only & -67145 & \\
\hline Log likelihood at convergence & & -28810 & \\
\hline Likelihood ratio index, $\rho^{2}$ & & 0.58 & \\
\hline
\end{tabular}

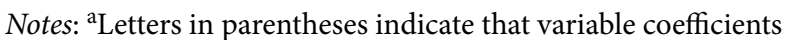
are significant specific to (N) No injury, (P) Possible injury, (I) Visible injury and (I/F) Incapacitating injury/fatality; The constants specific to the incapacitating injury/fatality outcome have been normalized to zero; ${ }^{\mathrm{b}}$ Estimated Coefficient; ${ }^{\mathrm{c}}$ Standard Error; The asterisk represents the level of significance: ${ }^{* *}$ for $>99 \%$ and ${ }^{\star}$ for $>95 \%$.

Table 5. Average variable pseudo elasticity for non-alcohol-influenced driver's model (\%)

\begin{tabular}{|l|c|c|c|c|}
\hline \multicolumn{1}{|c|}{ Variable } & $\begin{array}{c}\text { No } \\
\text { injury }\end{array}$ & $\begin{array}{c}\text { Possible } \\
\text { injury }\end{array}$ & $\begin{array}{c}\text { Visible } \\
\text { injury }\end{array}$ & $\begin{array}{c}\text { Incapacitating } \\
\text { injury/fatality }\end{array}$ \\
\hline Rural & -9.6 & 14.9 & 136.8 & 241.8 \\
\hline Stop sign & 7.4 & -30.1 & -30.1 & -30.1 \\
\hline $\begin{array}{l}\text { Signal } \\
\text { control }\end{array}$ & 2.3 & -4.4 & -27.0 & -27.0 \\
\hline $\begin{array}{l}\text { Multiple } \\
\text { vehicles }\end{array}$ & -9.6 & 45.8 & 45.8 & 45.8 \\
\hline Seatbelt & 64.3 & -63.7 & -63.7 & -63.7 \\
\hline $\begin{array}{l}\text { Passenger } \\
\text { car }\end{array}$ & -5.0 & 26.1 & 26.1 & 26.1 \\
\hline Female & -9.7 & 69.6 & 22.8 & 22.8 \\
\hline Left turn & -0.8 & -4.2 & 36.6 & 36.6 \\
\hline $\begin{array}{l}65 \text { years } \\
\text { or older }\end{array}$ & -1.3 & -5.6 & 54.0 & 54.0 \\
\hline
\end{tabular}

\subsection{Alcohol-influenced driver's model}

Table 6 shows the multinomial Logit model estimation results for alcohol-influenced drivers. The likelihood ratio index, $\rho^{2}$, is 0.41 , indicating the acceptable model performance. Many significant variables for non-alcohol-influenced drivers become less critical for alcoholinfluenced drivers, such as Stop sign, Signal control, Multiple vehicles, Seatbelt, Passenger car, Female, Left turn and 65 years or older, etc. For instance, the variable, Signal control, is found statistically insignificant to influence injury severities for alcohol-influenced drivers. It could be attributable to the facts that regulation and protection on vehicle movements from signal control become less recognizable and critical for drivers under the influence of alcohol passing through intersections. Therefore, it is insignificant to determine driver's injury severity outcomes. However, since only 638 records are used for developing and calibrating the alcohol-influenced driving crash model, additional research efforts are desirable to investigate further this research finding for its generality and transferability.

Noticeably, two new variables, Multi lanes and Straight, are found to be significant in the alcohol-influenced driver's model. The positive elasticities of the variable, Multi lanes, specific to Possible injury, Visible injury and Incapacitating injury/fatality, indicate that the probabilities of being possibly, evidently, and severely injured for alcohol-influenced drivers increase by $39.8 \%$ at intersections with three or more lanes on each approach relative to these with the other number of lanes. This result may be explained partially by the fact that traffic control and geometric conditions are more complex for intersections with multi-lanes on each approach so that alcohol influence becomes significant to increase the likelihood for drivers being injured at different levels, which is consistent with the previous studies (AbdelAty, Radwan 2000; Hu, Donnell 2011). Special countermeasures and policies should be developed to provide more visible warning messages to potentially alcoholinfluenced drivers at multi-lane intersections. Similar analyzes can be conducted for the variable, Straight. Its elasticities specific to Possible injury, Visible injury and Incapacitating injury/fatality are $36.2 \%$, indicating there are a $36.2 \%$ increase in the probabilities of being possibly and severely injured for alcohol-influenced drivers when they are traveling straight at intersections relative to the other actions, such as left turning, right turning, slowing, overtaking, U-turning, and backing. This could be because of the fact that alcohol-influenced drivers may be less cautious travelling straight through intersections at relatively high speeds which may indirectly result in more severe injuries. Similar results are also found in previous studies (Chang, Mannering 1999; Pai et al. 2009). Additionally, similar to the non-alcoholinfluenced driver's model, the variable, Rural, is found significant to increase alcohol-influenced driver's injury severities at intersection-related crashes as shown by its coefficient and elasticity in Tables 6 and 7, respectively. 
Table 6. Driver's injury severity model estimation for alcohol-influenced drivers

\begin{tabular}{|c|c|c|c|c|}
\hline Variable $^{\mathrm{a}}$ & Coef. $^{\mathrm{b}}$ & Std. ${ }^{c}$ & $T$-ratio & $P$-value \\
\hline Constant $(\mathrm{N})$ & 3.24 & 0.25 & 13.10 & $0.00\left(^{* *}\right)$ \\
\hline Constant $(\mathrm{P})$ & 0.89 & 0.22 & 4.10 & $0.00\left(^{* *}\right)$ \\
\hline Constant(I) & 0.71 & 0.22 & 3.18 & $0.00(* *)$ \\
\hline $\operatorname{Rural}(\mathrm{N})$ & -0.93 & 0.28 & -3.38 & $0.00\left(^{* *}\right)$ \\
\hline Multi lanes(N) & -0.47 & 0.24 & -1.99 & $0.05\left(^{*}\right)$ \\
\hline Straight(N) & -0.41 & 0.20 & -2.02 & $0.04\left(^{\star}\right)$ \\
\hline \multicolumn{3}{|c|}{ Log likelihood with constants only } & -884 & \\
\hline \multicolumn{3}{|c|}{ Log likelihood at convergence } & -526 & \\
\hline \multicolumn{3}{|c|}{ Likelihood ratio index, $\rho^{2}$} & 0.41 & \\
\hline
\end{tabular}

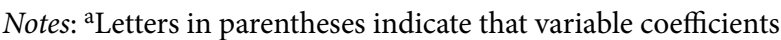
are significant specific to (N) No injury, (P) Possible injury, (I) Visible injury and (I/F) Incapacitating injury/fatality. The constants specific to the incapacitating injury/fatality outcome have been normalized to zero; ${ }^{b}$ Estimated Coefficient; ${ }^{\text {CStandard }}$ Error; The asterisk represents the level of significance: ${ }^{\star *}$ for $>99 \%$ and ${ }^{\star}$ for $>95 \%$.

Table 7. Average variable pseudo elasticity for alcohol-influenced driver's model (\%)

\begin{tabular}{|l|c|c|c|c|}
\hline Variable & $\begin{array}{c}\text { No } \\
\text { injury }\end{array}$ & $\begin{array}{c}\text { Possible } \\
\text { injury }\end{array}$ & $\begin{array}{c}\text { Visible } \\
\text { injury }\end{array}$ & $\begin{array}{c}\text { Incapacitating } \\
\text { injury/fatality }\end{array}$ \\
\hline Rural & -26.5 & 86.7 & 86.7 & 86.7 \\
\hline Multi lanes & -12.5 & 39.8 & 39.8 & 39.8 \\
\hline Straight & -9.4 & 36.2 & 36.2 & 36.2 \\
\hline
\end{tabular}

\section{Model Limitation Discussions}

Some discussions and elaborations are needed regarding data collection and model specifications in this study. The alcohol-related crash data were collected partially by reporting police officers based on their subjective judgments. Although testing drivers' BAC levels is the most accurate method to verify their alcohol consumption, it is only examined in fatal crashes in reality. For crashes of property damage only and injury, reporting police officers' subjective judgments play critical roles for alcohol-related crash data inputs. A certain number of crashes with minor or non-injury driver's injuries, which involved alcohol-influenced drivers, might not be reported due to less injury severities and drivers' willingness-to-pay for escaping punishment by law. Therefore, underreporting crashes of minor or non-injury has potentially occurred during crash data collection processes, which may further lead to biased model specification and estimation results. According to Kim et al. (2007) study, however, this only biases the coefficients when the underreporting is a function of the variables included in multinomial Logit models, such as age or gender, otherwise, the coefficients will remain unbiased under nonordered choice-based sampling processes. More accurate alcohol-related crash data collection is desirable to ensure reliable model specification and estimation results.

\section{Conclusions}

This study aims to model and examine the impacts of alcohol/non-alcohol-influenced driver behavior and demographic features as well as geometric and environmental characteristics on driver injury severities around intersections in the State of New Mexico from 2010 to 2011. The drivers involved in intersection-related crashes are classified into three groups based on their soberness status: all drivers, alcohol-influenced drivers, and non-alcohol-influenced drivers. Three multinomial Logit regression models were developed and calibrated to identify significant causal factors for three driver groups and to better understand how alcohol involvement impacts driver injury severities.

The model estimation results show that with respect to all drivers involved in intersection-related crashes, a combination of roadway geometric features, environmental characteristics, control modes, and driver attributes significantly impacted driver injury severities. Alcohol involvement is identified as a critical factor-determining driver's injury severities. Relative to non-alcohol-influenced drivers in intersection-related crashes, the probabilities of non-incapacitating injury and incapacitating injury/fatality for alcohol-influenced drivers increased by $284.0 \%$. This result implies that alcoholinfluenced drivers have a considerably high probability of suffering more severe injurious and fatal outcomes and underscores the necessity separating entire driver population into different groups: alcohol-influenced drivers and non-alcohol-influenced drivers for their specific attribute investigations. Interestingly, three significant factors are found to be non-monotonic to impact driver's injury severities, female, driver left turn action, and driver age group of 65 years or older. Many significant factors identified in the non-alcohol-influenced driver's model, including signal control and seatbelt use, become less significant for alcohol-influenced drivers given crash occurrences around intersections. However, three factors, rural, multi-lanes, and driver action of going straight, are still significant. Based on those results, appropriate countermeasures and policies can be proposed to mitigate driver injury severities in intersection-related crashes, especially for alcohol-influenced drivers. For instance, when a crash occurs due to driver left-turn movements, the probabilities of drivers being visibly, evidently and fatally injured increase by $35.3 \%$ compared with other driver actions, such as right turning, slowing, overtaking, U-turning, backing, and going straight. This result implies that due to driver left turn action; high fatality rates of non-alcohol-influenced drivers around intersections can be mitigated by adding appropriate traffic control restricting left turn behavior around intersections. For alcohol-influenced drivers, providing more visible warning messages to potentially alcohol-influenced driers at multi-lane intersections can effectively decrease the injury severity level of alcoholinfluenced divers.

Overall, this study provides a better understanding of contributing factors and their significant impacts on driver injury severities in crashes around intersections. 
The model specification and estimation results are also helpful for transportation agencies and decision makers to develop cost-effective solutions to reduce driver's injury severities especially of alcohol-influenced drivers, and improve traffic system safety performance. Additional research efforts are desirable to further investigation of the research findings using more comprehensive and accurate alcohol-related crash data for their generality and transferability. Furthermore, future studies are recommended to review current policies which have a direct impact on alcohol related crashes. Suggested policies include: the allowable driver BAC limit settings; Driving While Intoxicated (DWI) training; law enforcement strategies; and the driver license revocation policy. Further research is needed to estimate the effect of the present alcohol safety regulations and policies.

\section{Acknowledgements}

The authors gratefully acknowledge assistance with crash data from the NMDOT.

The interpretations are those of the authors and do not necessarily reflect the views of any organizations with which the authors have affiliations.

This research was funded in part by the National Natural Science Foundation of China (Grant No. 51138003 and 51329801).

\section{References}

Abdel-Aty, M. A.; Radwan, A. E. 2000. Modeling traffic accident occurrence and involvement, Accident Analysis \& Prevention 32(5): 633-642.

http://dx.doi.org/10.1016/S0001-4575(99)00094-9

Bédard, M.; Guyatt, G. H.; Stones, M. J.; Hirdes, J. P. 2002. The independent contribution of driver, crash, and vehicle characteristics to driver fatalities, Accident Analysis \& Prevention 34(6): 717-727.

http://dx.doi.org/10.1016/S0001-4575(01)00072-0

Chang, L.-Y.; Mannering, F. 1999. Analysis of injury severity and vehicle occupancy in truck- and non-truck-involved accidents, Accident Analysis \& Prevention 31(5): 579-592. http://dx.doi.org/10.1016/S0001-4575(99)00014-7

Demetriades, D.; Gkiokas, G.; Velmahos, G. C.; Brown, C.; Murray, J.; Noguchi, T. 2004. Alcohol and illicit drugs in traumatic deaths: prevalence and association with type and severity of injuries, Journal of the American College of Surgeons 199(5): 687-692.

http://dx.doi.org/10.1016/j.jamcollsurg.2004.07.017

Duncan, C.; Khattak, A.; Council, F. 1998. Applying the ordered probit model to injury severity in truck-passenger car rear-end collisions, Transportation Research Record: Journal of the Transportation Research Board 1635: 63-71. http://dx.doi.org/10.3141/1635-09

FHA. 2012. Highway Statistics 2010. US Department of Transportation, Federal Highway Administration (FHA), Washington, DC. Available from Internet: https://www.fhwa.dot. gov/policyinformation/statistics/2010

FHA. 2011. Our Nation's Highway 2011. US Department of Transportation, Federal Highway Administration (FHA), Washington, DC. 64 p. Available from Internet: http:// www.fhwa.dot.gov/policyinformation/pubs/hf/pl11028/ onh2011.pdf
FHA. 2009. Introduction to Intersection Safety Issue Briefs. Federal Highway Administration Safety Program FHWASA-10-005, US Department of Transportation, Federal Highway Administration (FHA), Washington, DC.

Gray, R. C.; Quddus, M. A.; Evans, A. 2008. Injury severity analysis of accidents involving young male drivers in Great Britain, Journal of Safety Research 39(5): 483-495.

http://dx.doi.org/10.1016/j.jsr.2008.07.003

Hu, W.; Donnell, E. T. 2011. Severity models of cross-median and rollover crashes on rural divided highways in Pennsylvania, Journal of Safety Research 42(5): 375-382.

http://dx.doi.org/10.1016/j.jsr.2011.07.004

Huang, H.; Chin, H. C.; Haque, M. M. 2008. Severity of driver injury and vehicle damage in traffic crashes at intersections: a Bayesian hierarchical analysis, Accident Analysis \& Prevention 40(1): 45-54. http://dx.doi.org/10.1016/j.aap.2007.04.002

IIHS \& NHTSA. 2006. Beginning Teenage Drivers. Insurance Institute for Highway Safety (IIHS), National Highway Traffic Safety Administration (NHTSA). Washington, DC. 8 p.

Islam, S.; Mannering, F. 2006. Driver aging and its effect on male and female single-vehicle accident injuries: some additional evidence, Journal of Safety Research 37(3): 267276. http://dx.doi.org/10.1016/j.jsr.2006.04.003

Khattak, A. J. 2001. Injury severity in multivehicle rear-end crashes, Transportation Research Record: Journal of the Transportation Research Board 1746: 59-68. http://dx.doi.org/10.3141/1746-08

Khorashadi, A.; Niemeier, D.; Shankar, V.; Mannering, F. 2005. Differences in rural and urban driver-injury severities in accidents involving large-trucks: an exploratory analysis, Accident Analysis \& Prevention 37(5): 910-921.

http://dx.doi.org/10.1016/j.aap.2005.04.009

Kim, J.-K.; Kim, S.; Ulfarsson, G. F.; Porrello, L. A. 2007. Bicyclist injury severities in bicycle-motor vehicle accidents, Accident Analysis \& Prevention 39(2): 238-251. http://dx.doi.org/10.1016/j.aap.2006.07.002

Kockelman, K. M.; Kweon, Y.-J. 2002. Driver injury severity: an application of ordered probit mode, Accident Analysis \& Prevention 34(3): 313-321. http://dx.doi.org/10.1016/S0001-4575(01)00028-8

Lau, M.; May, A. 1989. Accident Prediction Model Development for Unsignalized Intersections: Final Report. Research Report UCB-ITS-RR-89-12. Institute of Transportation Studies, University of California, Berkeley, US. 298 p.

Maistros, A.; Schneider, W. H.; Savolainen, P. T. 2014. A comparison of contributing factors between alcohol related single vehicle motorcycle and car crashes, Journal of Safety Research 49: 129-135. http://dx.doi.org/10.1016/j.jsr.2014.03.002

NHTSA. 2009. Traffic Safety Facts. 2009 Data: Alcohol-Impaired Driving. US Department of Transportation, National Highway Traffic Safety Administration (NHTSA), Washington, DC. $6 \mathrm{p}$.

NMDOT. 2010. New Mexico Comprehensive Transportation Safety Plan: 2010 Update. New Mexico Department of Transportation (NMDOT). 116 p. Available from Internet: http://dot.state.nm.us/content/dam/nmdot/planning/ NM_Comprehensive_Transportation_Safety_Plan.pdf

Neyens, D. M.; Boyle, L. N. 2007. The influence of driver distraction on the severity of injuries sustained by teenage drivers and their passengers, Accident Analysis \& Prevention 40(1): 254-259. http://dx.doi.org/10.1016/j.aap.2007.06.005 
O’Donnell, C. J.; Connor, D. H. 1996. Predicting the severity of motor vehicle accident injuries using models of ordered multiple choice, Accident Analysis \& Prevention 28(6): 739753. http://dx.doi.org/10.1016/S0001-4575(96)00050-4

Pai, C.-W.; Hwang, K. P.; Saleh, W. 2009. A mixed logit analysis of motorists' right-of-way violation in motorcycle accidents at priority T-junctions, Accident Analysis \& Prevention 41(3): 565-573. http://dx.doi.org/10.1016/j.aap.2009.02.007

Persaud, B.; Lord, D.; Palmisano, J. 2002. Calibration and transferability of accident prediction models for urban intersections, Transportation Research Record: Journal of the Transportation Research Board 1784: 57-64. http://dx.doi.org/10.3141/1784-08

Poch, M.; Mannering, F. 1996. Negative binomial analysis of intersection-accident frequencies, Journal of Transportation Engineering 122(2): 105-113.

http://dx.doi.org/10.1061/(ASCE)0733-947X(1996)122:2(105)

Renski, H.; Khattak, A. J.; Council, F. M. 1999. Effect of speed limit increases on crash injury severity: analysis of singlevehicle crashes on North Carolina interstate highways, Transportation Research Record: Journal of the Transportation Research Board 1665: 100-108. http://dx.doi.org/10.3141/1665-14

Retting, R. A.; Weinstein, H. B.; Solomon, M. G. 2003. Analysis of motor-vehicle crashes at stop signs in four U.S. cities, Journal of Safety Research 34(5): 485-489. http://dx.doi.org/10.1016/j.jsr.2003.05.001

Savolainen, P.; Mannering, F. 2007. Effectiveness of motorcycle training and motorcyclists' risk-taking behavior, Transportation Research Record: Journal of the Transportation Research Board 2031: 52-58. http://dx.doi.org/10.3141/2031-07

Sayed, T.; Rodriguez, F. 1999. Accident prediction models for urban unsignalized intersections in British Columbia, Transportation Research Record: Journal of the Transportation Research Board 1665: 93-99. http://dx.doi.org/10.3141/1665-13

Shankar, V.; Mannering, F. 1996. An exploratory multinomial logit analysis of single-vehicle motorcycle accident severity, Journal of Safety Research 27(3): 183-194. http://dx.doi.org/10.1016/0022-4375(96)00010-2

Smink, B. E.; Ruiter, B.; Lusthof, K. J.; De Gier, J. J.; Uges, D. R. A.; Egberts, A. C. G. 2005. Drug use and the severity of a traffic accident, Accident Analysis \& Prevention 37(3): 427-433. http://dx.doi.org/10.1016/j.aap.2004.12.003

Train, K. E. 2009. Discrete Choice Methods with Simulation. 2nd edition. Cambridge University Press. 400 p.

Traynor, T. L. 2005. The impact of driver alcohol use on crash severity: a crash specific analysis, Transportation Research Part E: Logistics and Transportation Review 41(5): 421-437. http://dx.doi.org/10.1016/j.tre.2005.03.005

Ulfarsson, G. F.; Mannering, F. L. 2004. Differences in male and female injury severities in sport-utility vehicle, minivan, pickup and passenger car accidents, Accident Analysis \& Prevention 36(2): 135-147.

http://dx.doi.org/10.1016/S0001-4575(02)00135-5

Wang, J.; Zhang, G. 2011. Modeling and examining the teenage and adult freeway crash risks and injury severities in Washington State, Journal of Transportation Safety \& Security 3(3): 207-221. http://dx.doi.org/10.1080/19439962.2011.591518

Washington, S. P.; Karlaftis, M. G.; Mannering, F. L. 2003. Statistical and Econometric Methods for Transportation Data Analysis. Chapman and Hall/CRC. 440 p.
Williams, T.; Alves, P.; Lachapelle, G.; Basnayake, C. 2012. Evaluation of GPS-based methods of relative positioning for automotive safety applications, Transportation Research Part C: Emerging Technologies 23: 98-108. http://dx.doi.org/10.1016/j.trc.2011.08.011

Yamamoto, T.; Shankar, V. N. 2004. Bivariate ordered-response probit model of driver's and passenger's injury severities in collisions with fixed objects, Accident Analysis \& Prevention 36(5): 869-876. http://dx.doi.org/10.1016/j.aap.2003.09.002

Zador, P. L. 1991. Alcohol-related relative risk of fatal driver injuries in relation to driver age and sex, Journal of Studies on Alcohol and Drugs 52(4): 302-310.

http://dx.doi.org/10.15288/jsa.1991.52.302 